\title{
Chapter 13 \\ The Process of Merging Romanian \\ Universities: Technical University \\ of Cluj-Napoca - North University \\ of Baia Mare
}

\author{
Radu Munteanu and Dan Călin Peter
}

\subsection{Introduction}

The chapter starts by highlighting a number of defining elements in the way the merger process of the North University of Baia Mare (NUBM) and the Technical University of Cluj-Napoca (TUC-N), was conducted, within the enabling context provided by the law of National Education (LNA No 1/2011). The vision to promote the merger of Romanian universities was based on brainstorming sessions and consulting with the partners involved, including prominent personalities from higher education, experts in economic and financial fields, and representatives of public and political life. Before 1989, only $10 \%$ of the population in the 20-24 year echelon proceeded to university studies, a situation which improved significantly in the 1989-2009 period. This positive evolution in the last 20 years has taken place despite unfavourable financial circumstances and the threefold increase in the number of universities at national level as compared to a parallel eightfold increase in the number of students.

The higher education system in Romania consists of a total of 112 public and private universities $(56+56)$, not taking into account the other five higher education institutions which only offer Masters and Postgraduate programs. According to the Statistical Yearbook of Romania 2011 edition, the 112 universities have a total of 775,000 students and a teaching staff complement of 31,000 people. However, in the last 4 years, according to the Romania in Figures 2013 publication, it was noted that the number of students have undergone a serious contraction: from 775,000 in

\footnotetext{
R. Munteanu

Technical University of Cluj-Napoca, Cluj-Napoca, Romania

e-mail: radu.munteanu@mas.utcluj.ro

D.C. Peter $(\bowtie)$

Technical University of Cluj-Napoca, North University Centre of Baia Mare,

Baia Mare, Romania

e-mail: dcpeter@ubm.ro
} 


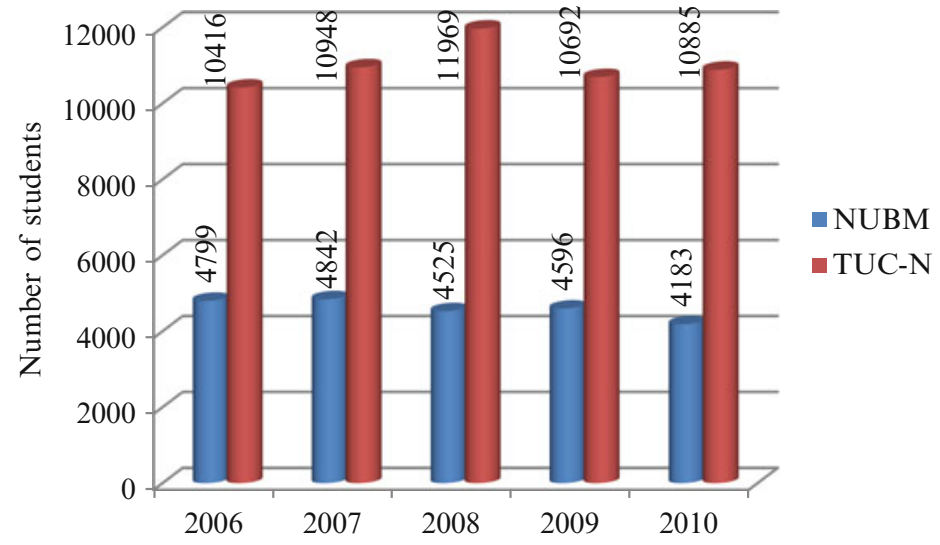

Fig. 13.1 The dynamic of students in the Bachelors' cycle before the merger

2009-2010 academic year to 464,000 in 2012-2013 academic year, a decrease from 361 to 218 students per 10,000 inhabitants whilst in the same period, the number of teaching staff decreased from 31,000 to 27,000. Figure 13.1 presents the fluctuation in the number of Bachelors' students at the two universities in the period before the merger (2005-2010), which shows a declining trend in the number of students, especially at the NUBM.

While for years higher education has promoted the spirit of competition through knowledge, in contemporary society education must take into account the importance of sharing resources and engaging in partnerships. People everywhere now have an acute motivation to assimilate science through education, regardless of their professional background, and they are aware of the benefits accruing from the development of related technologies. This phenomenon is not simple, because the same people also have a definite need for culture, philosophical, historical and even artistic, the more they use technical achievements, in order to understand more correctly the significance of their own acts. Thus the synergy generated by the universities through a larger and more varied professional offer is beneficial at many different levels.

The Quality Barometer (2010 edition) provides a chronology of Romanian universities, indicating that only $18 \%$ of universities have been in existence for over 100 years, whilst $50 \%$ are only 20 years old. The main issue is not related to their post-revolution age, but the low level of institutional diversity, although the majority declares a national vocation in their Charter. After 1990, the universities began to resemble each other more and more and this induced a level of depersonalization. The reasons are multiple and are largely linked to "standardized" implementation, due to unitary funding which does not stimulate institutional differentiation through quality and excellence. In this regard, the younger or smaller universities were particularly disadvantaged and often were not able to conform to the legislation regarding quality assurance and accreditation. 
These universities have encountered major problems in their development due to the fact that the global funding has systematically been kept at a low level, and the national budget for the educational system never exceeded $4 \%$ of GDP. There was an increasing trend in higher education funding after 2003 and in 2007 the allocations $(1.12 \%)$ equalled the European average (National institute of statistics 2013). However, after that there was a systematic regress in funding with a lowering of the allocation of GDP to higher education of $0.53 \%$ in 2010 . This is the context in which the paradox of "high necessity for education and minimal resources" appeared. This was a key factor which affected the North University of Baia Mare, which provides educational services at university level in a region which is important economically and demographically.

The rationale for the merger related to the concept of synergy and its effects in concentrating material and human resources for increasing the (didactic and scientific) performance and efficiency of the educational system associated with an ascendance of the visibility of universities. In this context, a coherent vision for the merger was developed, which was accepted by both university senates. The managerial competencies required by the process, and the factors of success were identified, taking into account the mentality and the elements of risk (Băcanu 2006). It is important to note that this premiere merger of two universities in Romania has been followed with interest by the academic community and beyond. It is unlikely that this merger will be followed in the near future by other mergers or university consortia based on consent.

\subsection{Background}

The chronology of events in the setting up of the Technical University of Cluj-Napoca and the North University of Baia Mare and their merger, reflects a succession of legislative and policy developments. In 1961, through a Decision of the Council of Ministers (No. 547/30.08.1961), the Pedagogic Institute, was set up in Baia Mare, for a 3 year period, with three faculties: Philology, Mathematics, and Natural and Agricultural Sciences. In 1969, through a Decision of the Council of Ministers (No. 1322/12.06.1969) published in the Official Gazette of Romania (No. 64/16.06.1969), the Institute of Sub-engineers from Baia Mare was established, subordinate to the Polytechnic Institute of Cluj (the current Technical University of Cluj-Napoca). Later, in 1984, the State Council Decree No. 213 from the 23rd of June 1984, certified that the Institutes of Sub-engineers from Baia Mare, Târgu Mureş, Oradea and Sibiu would be subordinate to the Polytechnic Institute of Cluj-Napoca. The situation remained the same until 1990, when these entities became independent, and in 1992, the Polytechnic Institute became the Technical University of Cluj-Napoca.

In 1990, the Institute of Higher Education of Baia Mare was founded through the Order of the Ministry of Education No. 7751/15.05.1990. In 1991, based on the Note of Government from 4.01.1991 and on the Order of the Ministry of Education and Science No. 4894 from 23.03.1991, the institution was re-named the University 
of Baia Mare. In 1996, through a Decision of the Government (No. 1241/ 20.11.1996) published in the Official Gazette of Romania No. 314/28.11.1996, the institution's name changed to the North University of Baia Mare.

\subsection{The Merger Process}

The majority of developing countries and countries in transition continue to encounter difficulties in addressing persistent/long-running challenges due in great part to inadequate responses. These include ways of broadening the area covered by tertiary education in a sustainable manner; reducing inequalities linked to accessing and exiting the tertiary education system; improving the quality and the relevance of the educational system; and introducing governance structures and efficient management practices (Shattock 2003). Although the total number of student places at tertiary level has significantly increased in all developing countries, the gap separating the most advanced economies from the developing world has also increased. Furthermore, tertiary education systems continue to have a strong elitist character. The financial resources allocated have proven to be insufficient to sustain the increase in both student places and the quality of educational processes (Dumitrache and Munteanu 1998). In many countries, the rigid governance models and management practices prevent tertiary education institutions from coping adequately with change and from launching the necessary measures in the direction of reform and innovation.

Tertiary education institutions can play a critical role in assuring the necessary support for the implementation of strategies for economic growth based on knowledge. They also play a key role in building democratic societies, with a high level of social cohesion, by offering adequate/accessible education, training and research programs. In response to this need, the merger of universities could form part of the national strategic vision for higher education in the future.

\subsubsection{The Case for the Merger}

For the two universities engaged in this merger, the main case for merging was the need to develop a structure to support the development of higher education in Baia Mare in response to major difficulties of sustainability which it was facing. In this context, the TUC-N, having within its strategic policy a component aimed at homogeneous development to ensure the highest possible level of quality in higher education and education in Transylvania, analyzed these trends and decided to support the North University of Baia Mare. The strong historic and current links with the North University of Baia Mare and the fact that a large component of the teaching staff was from Cluj, led TUC-N to decide from 2011 to support the NUBM by providing over 600 budgeted admission seats from its own allocation, in order to ensure the functioning of its partner. 


\subsubsection{The Stages of the Merger}

The universities embarked on the merger discussions in 2010 within the context of particular legislation and the actual conditions in the Romanian higher education. Figure 13.2 provides an overview of the merger procedure, in time, through the regulatory decisions of the evolution stages.

This was the first step and the effects were felt immediately. Then, consultation and analysis (including SWOT - Fig. 13.3) took place at the level of the senates and of the administrative managements. The feasibility study was undertaken using modern methods of communication between the two entities, and based on a simulation of their integrated management. Taking into consideration the fact that

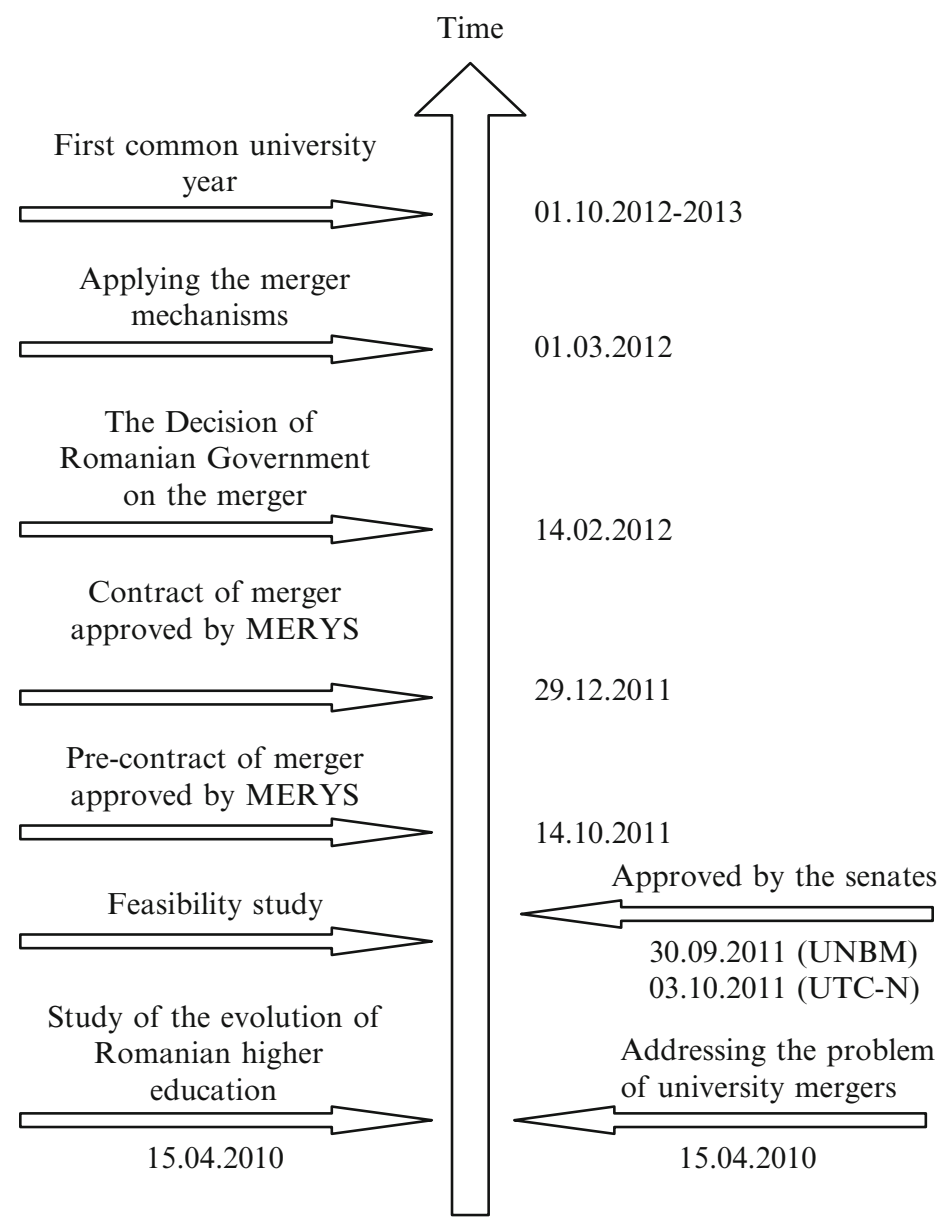

Fig. 13.2 Evolution in time of the merger through absorption mechanism between the TU Cluj-Napoca and the NU Baia Mare 


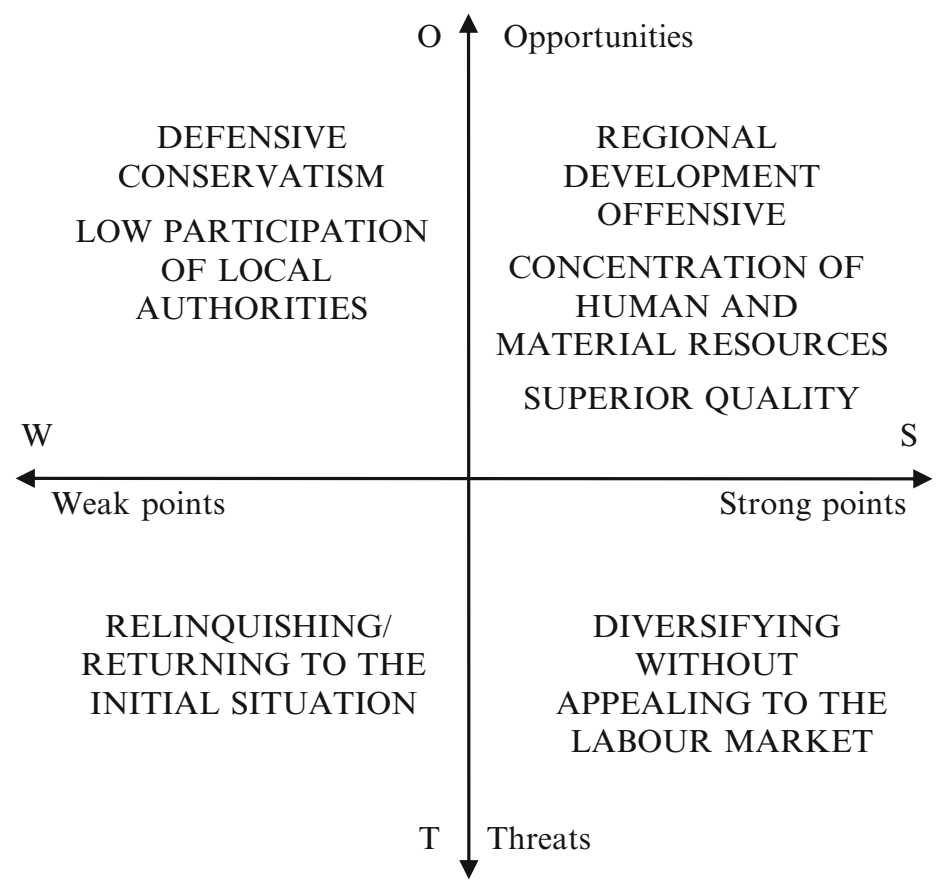

Fig. 13.3 SWOT interpretation of the merger through absorption strategy

the merger would fit with the European education perspective, the Senates independently approved the merger agreement proposal for absorption by the TUC-N. The Senates' decision was validated by the Ministry (29.12.2011) and followed by enactment of legislation through the Decision of the Romanian Government regarding the merger (14.02.2012).

Based on preliminary studies carried out since 2010, (starting with 1.03.2012), the universities proceeded with the application of the merger mechanisms and with reforming the structures of the two entities, such that the first joint academic year was launched on 1 November 2012. It is important to note that the main changes implemented related to efficiency mechanisms and increase in quality, both of which were an area of success. Thus, in 2013, the university was awarded the "high degree of confidence" (Drucker 2007) rating by the RAQAHE (ARACIS) The Romanian Agency for Quality Assurance in Higher Education. This recognition has considerably increased the effort to introduce reform at Baia Mare.

\subsubsection{Conditions of the Merger}

A modern institution of tertiary education needs an integrated process of strategic planning. Such a process must be oriented, from an organizational point of view, towards both the internal and external environment. It has to simultaneously 
consider planning intervals of 10,5 and 3 years. The modern institutions of tertiary education resulting from a merger are usually much more complex than the educational models that preceded them (Brătianu 2004). The new accents on partnerships, alliances, interdisciplinary programs and on access to other institutional programs require the administrative structures to be flexible and capable of adjusting the ways of delivering services according to the needs of students, clients and funding entities. Furthermore, the majority of institutions consider the granting of a certain degree of autonomy even at the lowest academic levels to be a value generating factor. But in order to allow for the coexistence of a healthy financial control system and an autonomous decision making system, the institutions concerned must have excellent internal communication mechanisms, systems and procedures which can offer the certainty that the same information reaches every level of the organization. The emergence of a modern institution of tertiary education (resulting from the merger) depends on the implementation of an integrated information system for the coordination of three essential components: human resources, financial resources and students. The integration of the informational system is necessary to reduce transfer errors and to assure the uniformity of information at every level.

The most important framework conditions forming the basis of the merger relate to the following four factors:

- At the time when the Contract of merger by absorption was formally adopted in accordance with the Law of University Consortia No. 287/2004, the Technical University of Cluj-Napoca, as the absorbing unit, kept its status of accredited higher education institute and its law of establishment, while the law establishing the North University of Baia Mare, as the absorbed unit, was repealed.

- The rights and obligations of the absorbed institution passed to the absorbing unit.

- TUCN, as the absorbing unit, took over the entire heritage of the NUBM (absorbed unit).

- After the merger, a complex functional unit was established at TUC-N, corresponding to the absorbed unit, without legal personality, and entitled North University Centre of Baia Mare (NUCBM), which was directly subordinate to the TUC-N Senate and its Rector.

The conditions of the merger were defined following this staged approach:

- Discussions with the teaching staff at departmental and faculty level on the opportunity to undertake a merger between the two universities (addressing benefits and concerns on both sides).

- The decisions taken by the two academic Senates relating to the merger (Decision of the NUBM Senate from 30/09.2011 and Decision of TUC-N Senate from 03.10.2011).

- The pre-contract of the merger, approved by the Ministry of Education, Research, Youth and Sports (MERYS) (14.10.2011). It establishes the conditions of the merger, the rights and obligations of both sides, the patrimony and also a strong commitment of both universities to sign a contract of merger through absorption in authentic form before the 3rd of January, 2012. 
- The contract of merger through absorption formally signed by the two universities and approved by MERYS (29.12.2012).

- Government Decision dated 14.02.2012 which states that the following four faculties of the NUBM: Faculty of Engineering (FE), Faculty of Mineral Resources and Environment (FMRE), Faculty of Humanities (FH) and Faculty of Sciences (FS), are to form part of the structure of the TUC-N and to function within the NUCBM.

The results of the study regarding the merger process are presented synthetically in a SWOT-format interpretation of the projected strategy (see Fig. 13.3).

\subsection{The Operating Principles of the New Structure (the North University Centre of Baia Mare Within the Technical University of Cluj-Napoca)}

The operating principles of the North University Centre of Baia Mare within the Technical University of Cluj-Napoca were agreed by the two institutions and are stipulated in the Contract of the merger. They refer to both academic activity and the financial and administrative aspects. The cardinal elements that establish the operation of NUCBM, the absorbed entity within the Technical University of Cluj-Napoca, were defined with the leadership of the NUCBM assured through the Vice-Rector, who is appointed by the TUCN Rector's decision and by a Coordination Council from NUCBM, in an advisory role (Rusu 2003). Their mandate is for a 4 year period.

The Coordination Council of NUCBM consists of the coordinating Vice-Rector, the deans, directors of departments within the centre, the administrative director and the head of the financial - accounting office from the NUCBM, as well as representatives of the students. Its activity is established in the operating regulation approved by the TUC-N Senate.

The financial administration is carried out in accordance with applicable laws and the TUC-N Charter, by a local financial and accounting office led by a head of office. The office reports to the Vice-Rector of NUCBM and to the financial and accounting department of TUC-N.

The funding of CUNBM follows the principle of financial decentralization, applied in the TUC-N. Thus, local own income from fees, income from donations, sponsorship, contracts or any other legal sources remain part of the NUCBM's disposable income, while the income from core funding is distributed to the NUCBM in accordance with the number of its students, after the deduction of the administration fee established by the TUC-N Senate. Subsidies for housing and canteen will be distributed in accordance with the number of accommodated students in the student hostels administered by the NUCBM, and the income from student hostels and canteen self-financing remain at the disposal of the NUCBM. The funds related to scholarships and other forms of social protection 
awarded to the students of NUCBM from the budget of the MERYS are managed by the NUCBM.

The administrative activity is carried out in the framework of a local department lead by a deputy general director, in accordance with the applicable laws and with the TUC-N Charter. The department reports to the Vice-Rector of NUCBM and to the General Administrative Direction of the TUC-N. Activities such as acquisitions, human resources, audit, international relations, library are carried out within the departments, bureaus and offices in the structure of the NUCBM, reporting both to their corresponding departments within the TUC-N as well as to the coordinating Vice-Rector of NUCBM.

\subsection{Beneficial Effects and Deficiencies of the Merger Process}

The immediate impact of the merger was apparent in a number of beneficial outcomes for the NUCBM. Thus, the joint management of the student places has resulted in a better distribution of funded places and a diversified offer which covers a larger geographical area and thus a larger educational space, thus meeting the demand from candidates with modest financial possibilities. The TUC-N gave temporary financial support for viable study programmes within the NUCBM, which are currently in deficit. In the medium- and long- term, the aim is to render more compatible the performance of the two entities, with an emphasis on improving performance in terms of student training and scientific research activity (Chiorean 2011). A concrete plan of action in this context is already in place. Thus, the first visible effects relate to the development of a better institutional management, taking into consideration inter- and cross-subject activity.

From a content point of view, another benefit of the merger is the expected involvement of the NUCBM in the TUC-N departments in Satu-Mare, a city located near Baia Mare. In this context, the new entity of the Technical University of Cluj-Napoca will be engaged in the regional academic program, including the TUC-N extensions in Satu-Mare, Bistriţa, Zalău and Alba Iulia. This recommends the TUC-N as a major player in the process of regionalization in the NorthernWestern area of Romania.

The correlation of the education and research programs is a core element of the merger process, for the common study programs run in Cluj-Napoca and Baia Mare. This process is currently underway and it will be extended over the study cycle (Hockley 2007).

The merger of the two universities is the first such action in Romania, which is why there were and still are several difficulties encountered. This is partly due to the fact that the legislation does not address all aspects of merger implementation. In addition, other difficulties are linked to the mentality and the process of adapting to the new situation. The merger has been conducted based on the Law of National 
Education (No. 1/2011) and the Law of University Consortia (287/2004), which outline the general principles but are not accompanied by a clear methodology which stipulates the approach and procedures to be adopted at all the stages of the merger. This deficiency has been addressed by including details on the stages and procedures to be used in the merger process into the merger contract, with the agreement of both institutions. The Law of National Education makes the following provision in art. 194(2): "MERYS (Ministry of Education, Research, Youth and Sports) preferentially allocates financial resources to consortia or merged universities, according to a methodology adopted in this regard through the order of the minister of education, at the proposal of the NCFHE (National Council for Financing Higher Education)" (Romanian ministry of education 2001). This methodology has not been adopted up to the present time, which means the MERYS has not financially supported the process or merger and this implies additional expenses linked to the operational communication and the integrated management of the two entities among others.

Administrative harmonization between the two entities was and is necessary because, before the merger, the two units had different internal regulations and procedures. The process of administrative harmonization, which started immediately after the merger took effect, was undertaken with certain difficulty. The procedures which were considered most effective by both entities were kept and developed further. Another deficiency which occurred after the merger relates to the operational communication at the level of the Administration Council and of the Senate. The NUCBM is represented both in the Administration Council and in the Senate, based on the same rules applied in the absorbing university, mainly in accordance with the existing faculties and the number of students. In the first few months after the merger, members of the Administration Council and of the Senate had to spend considerable time travelling to Cluj-Napoca for work meetings. The problem was resolved through the acquisition and operation of the necessary equipment for videoconferences. The conservative mentality of local authorities also represented a deficiency for the merger as they did not understand the benefits of the two universities joining forces and their patrimony. This was largely due to the lack of sufficient information and communication on the merger process or due to ignorance. The pressure to adapt to the new situation exists and will disappear in time as the effects of the merger process have had time to mature and to be accepted.

The merger of the North University of Baia Mare with the Technical University of Cluj-Napoca has been an experience both institutions tried to manage with maximum attention and openness from the beginning, taking into consideration both the strong and weak aspects determined by internal and external evaluations. The main administrative problems were overcome through the exercise of correlation and integration of services related to Direction of Administration, Personnel Salaries, Accountancy and Audit. These services kept their status at NUCBM level, with dual reporting to the Rector of the TUC-N and the Vice-Rector of the NUCBM.

The faculties within the NUCBM retained their identity, but they assimilated constructively the management structure which allows them natural integration 
within the TUC-N. The presence of the Vice-Rector appointed to take charge of the management of the NUCBM and of the deans of all four faculties in the Board of Administration of the TUC-N allows a permanent connection to the current and future issues of the institution. This enables as much as possible an understanding and perception of the merger process as a correct and beneficial process, for both the former NUBM and the TUC-N. The Coordination Council of the NUCBM allows and will further allow in the future a facility for the prompt management of specific issues facing the NUCBM, so that they do not escalate into sources of misunderstanding and conflicts.

Of the four faculties of the NUCBM, the Faculty of Humanities will remain a unit with particular features which the management of the TUC-N will have to take into account. The differences are not only of a financial nature regarding the coefficient of budget funding, but also relating to its main mission, of training teachers for preschool, primary, gymnasium and high school education. This also has repercussions on the content of research, which is based on the idea of training (usually poorly rated and financed). The joint efforts of the management of the Faculty of Humanities and of the TUC-N have as result developed a custom projection of all its entities functioning on the principle of unity in diversity.

\subsection{Conclusions}

In the current situation in Romania and taking into consideration the economic and the demographic conditions and the prospective of administrative reorganization in the development regions, mergers between universities are a process worthy of close attention. Based on to the current population, it is envisaged that based on a generous estimate, there is a university population of below 200,000 in Romania, under conditions of a constant decrease of the school population. Furthermore, the economic market cannot absorb large categories of university educated youth, creating a context in which unemployment of university graduates is a major threat for the future. In this situation, administrative restructuring with the institutional aspects of decentralization will require a different positioning of the educational system, in accordance with labour market requirements. It is envisaged that the perspective of post-secondary school development, linked to the qualifications highly required by the economy and correlated with the normally higher and higher exigency of the baccalaureate, will naturally decrease the student population. The merger of universities is a complex process which is linked to an uncertainty about the future that is fuelled by tradition. It is a complex form of innovation, which will affect traditional operations in a major way in the near future and this is the reason why a new long term strategy is recommended complemented by extensive awareness-raising.

In the last few years, new institutions with an educational vocation in the tertiary field have emerged worldwide, together with new forms of competition, forcing traditional institutions to change their mode of operating and supplying educational 
services, in order for them to benefit from the opportunities offered by new technologies in the field of computers and communications (Munteanu et al. 2009). These have become intrinsic performance accelerators, but also provocateurs for the merger of universities. In this context, the merger can be defined in a variety of ways. In a systemic vision, it can be defined as a set of capabilities and expertise, shared among several actors capable of a joint strategy (Munteanu et al. 2010). Finally, it can be understood from our brief experience, that all universities have resources, but not all are capable of using them efficiently. The existence of resources alone is not sufficient to drive a merger process, because the traditional actors are generally reluctant to undergo major changes.

In conclusion, through this merger, the Technical University of Cluj-Napoca strengthened its regional network of higher education in Transylvania, including besides Baia Mare, academic education centres in Alba Iulia, Bistriţa, Zalău and Satu Mare. This is the context in which in future it will become an important player in the educational politics of the development region in this part of Romania. The merger is a long-lasting process. The complete integration of the absorbed unit in the absorbing unit will take at least a cycle of study, because implementing common curricula and regulations can only be done in year I of study. From a different perspective, the merger exercise undertaken represents a process of passage from hierarchies to university networks, leading in turn to another passage, from an exclusive development option to multiple options. Although deficiencies were encountered, the academic community is confident of being able to achieve the objectives of increasing quality in the educational and research process and enhancing the university's national and international visibility as a whole.

Open Access This chapter is distributed under the terms of the Creative Commons Attribution Noncommercial License, which permits any noncommercial use, distribution, and reproduction in any medium, provided the original author(s) and source are credited.

\section{References}

Băcanu, B. (2006). Practices of strategic management. Methods and case studies. Iaşi: Polirom Publishing.

Brătianu, C. (2004). Entrepreneurial dimensions in the Romanian higher education. Letters from the Black Sea. International Journal of the Black Sea Universities Network (Vol. May, pp. 34-37).

Chiorean, L. (2011). Study and research regarding the performance of the university management. Doctorate thesis, Technical University of Cluj-Napoca.

Drucker, P. (2007). Management: Tasks, Responsibilities. New Brunswick: Transactions Publishers.

Dumitrache, I., \& Munteanu, R. (1998). Problems of the higher education reform. Bucharest: Alternative Publishing.

Hockley, A. (2007). Educational management. Iaşi: Polirom Publishing. 
Munteanu, R., et al. (2009). Modern methods of technological education using virtual environment. In Proceedings of the 6th international conference on management of technological changes (Vol. 2, pp. 303-306). Tulcea, Romania.

Munteanu, R., et al. (2010). Teaching the messenger generation. In Proceedings of the 6th international seminar on quality management in higher education (2nd ed., pp. 171-174). Tulcea, Romania.

National institute of statistics (2013). Romania in figures 2013 - Statistic summary. [Online] Available at: http://www.insse.ro/cms/files/publicatii/Romaniaincifre2013_ro.pdf

Romanian ministry of education (2001). The strategy of Romanian higher education on 2002-2010 period. [Online] Available at: http://www.edu.ro/index.php/articles/2884

Rusu, C. (2003). The management of change. Bucharest: Economic Publishing.

Shattock, M. (2003). Managing successful universities. New York: Society for Research Higher Education \& Open University. 